\title{
Making sense of Bolkestein-bashing: trade liberalization under segmented labor markets
}

\author{
Gilles Saint-Paul* \\ Université de Toulouse 1, CEPR and IZA
}

October 23, 2006

\begin{abstract}
Trade liberalization is often met with sharp opposition. Recent examples include the so-called "Bolkestein" directive, which allows service providers from a given EU member to temporarily work in another member country. One way to view such a reform is that it simply widens the range of goods that are tradeable. This kind of reform is analyzed in a two-country Dornbusch-Fischer-Samuelson style model, where labor cannot relocate to another sector upon a non expected increase in the range of goods that can be traded.

The effect of liberalization on the terms of trade tend to favor the poorer country (the "East"), if (as assumed) the most sophisticated goods are tradeable before reform. Second, under ex-post liberalization, there exists a class of workers in the West who are harmed because they face competition from Eastern workers and cannot relocate to other activities. But if the East's economy is relatively small, their wage losses are not very large. Things are different, however, if there exist asymmetries in labor market institutions, such that upon reform, labor can relocate in the East but not in the West. Some workers in the West can then experience very large wage losses. Thus, rigid labor markets in the West magnify opposition to reform there.
\end{abstract}

JEL: F16, F11, F13.

Keywords: Trade liberalization, European integration, Bolkestein directive, labor mobility, labor market institutions, comparative advantage, terms of trade.

*I am grateful to seminar participants at the Bank of Italy; IGIER, Bocconi University; the European University Institute; the European Summer Symposium in Labour Economics, Ammersee; the University of Essex; The INTAL conference, IADB, San Jose de Costa Rica; the editor, Kala Krishna, and two anonymous referees for helpful comments and suggestions. 


\section{Introduction}

Trade liberalization is often met with sharp opposition. Recent examples include concern about a sharp increase in textile imports from China into the European Unions (following the phasing out of the multi-fiber agreement (MFA)), as well as complaints in France and other EU countries against the so-called "Bolkestein" directive, which allows service providers from a given EU member to temporarily work in another member country, under the regulatory regime prevailing in the source country. Thus, a Polish plumber or hairdresser could freely offer his services in France, while not being bound by French labor law and other local regulations, provided his stay is short enough. One way to view such a reform is that it simply widens the range of goods that are tradeable: haircuts and plumbing services can now be purchased "in Poland", with the twist that the worker performing the service has to be moved to France, and then back to Poland, which is a particular form of transportation cost.

While part of the complaints have to do with the fact that French labor laws impose a tax on labor which is higher than in Poland, the bottomline is that Polish wages are a third of French wages (they would thus remain much lower even with similar labor market regulations), so that French plumbers and hairdressers simply feel they are going to disappear. Similar concerns are voiced about textile jobs disappearing because of Chinese imports, or offshoring to India of services such as call centers or consumer banking.

Economists usually interpret resistance to such reforms through the lens of the Stolper-Samuelson theorem. It says that the return to the relatively scarce factor is bound to fall when an economy opens to trade, so that if compensatory transfers are not feasible, some social groups would oppose liberalization.

The problem with this view is that one then has to conceive of French hairdressers as part of a larger group, the "unskilled", who, if scarce relative to the East, suffer of any trade intensive in unskilled labor. Thus, there is no reason 
why French hairdressers should complain more about Polish hairdressers than about, say, Polish textiles, or indeed about competitions from the millions of unskilled unemployed in the French labor market. Furthermore, if there are only a few skill categories, then trade in just that number of goods is enough to bring about factor price equalization. Further increases in the range of tradeable goods should not have any additional harmful effects on the scarce factor, while it can bring beneficial effects if there are increasing returns to scale ${ }^{1}$.

One way to solve this paradox is to think about resistance to reform in terms of a segmented labor market where moving between occupations is costly. If labor markets were perfect, any adverse effect of liberalization in haircuts would be diluted in the form of a lower unskilled wage in the economy, and would not be particularly concentrated on hairdressers. However, if labor markets are segmented, in that moving to an occupation is difficult (at least in the short run), then each occupation becomes a different kind of labor input, and it is conceivable that liberalizing trade in haircuts would have large adverse effects on French hairdressers, who are prevented from relocating to other occupations. These, in turn, are sheltered from the downward pressure on unskilled wages exerted by the reform. Thus, labor rigidities concentrate losses upon the occupations that are liberalized.

One may add that regulatory entry barriers play an important role in generating labor market segmentation. These barriers are well documented. For the French case, for example, a number of them are reported by Cahuc and Kramarz (2004). For example, a lot of professions (hairdressers, butchers, veterinaries...) cannot be entered without a specific degree, which often involves academic skills not needed to perform the task. Clearly, such requirements make it very difficult to enter these professions at a late date in one's life cycle. Other types of barriers to professional mobility include entry quotas and exclusive territories, that are prevalent for taxis and pharmacies.

\footnotetext{
${ }^{1}$ Such effects, well understood since Helpman and Krugman (1985), are left out of our analysis here.
} 
If such barriers did not exist, the professions that are threatened by the Bolkestein directive would have already suffered much more from competition from the unemployed. In a country such as the UK, these barriers are much lower, and, accordingly, opposition to the directive is much smaller: because of labor mobility, existing trade in commodities already largely determines factor prices, and one might not expect much action on the inequality front when further liberalization takes place.

This paper analyzes the distributional effects of trade reforms when labor markets are segmented. It uses a Ricardian model in the fashion of DornbuschFischer-Samuelson (1977, hereafter DFS). There are two countries, East and West, and the key assumptions being made are:

-Goods can be ranked by level of sophistication; the relative productivity of the East is lower in more sophisticated products. Thus the West has a comparative advantage in these products.

-Goods below a certain level of sophistication are non traded; this captures the fact that greater sophistication is associated with industrial products, while lower sophistication is associated with services.

-Trade reform consists in broadening the range of goods that are tradeable. This stands in contrast to most of the literature, which typically considers a uniform reduction in tariff levels. ${ }^{2}$ It is meant to capture reforms like the disputed service directive mentioned above, which increases the range of tradeable goods. $^{3}$

-Trade reform will therefore reduce the critical sophistication level which separates tradables from non tradables. Thus, the new tradables are less sophisticated than the existing ones; at the margin, they should be produced by the East.

-Workers have to choose which sector to work in before trade liberaliza-

\footnotetext{
${ }^{2}$ Here we have, in some sense, an extreme case of a non-uniform reduction in tariffs, since tariffs fall from infinity to zero for the newly traded goods, and are unchanged for other goods.

${ }^{3}$ The phasing out of the MFA is a more mixed kind of policy, since a subset of goods is made "more" tradeable.
} 
tion takes place. Therefore, if haircuts are made tradeable, French hairdressers cannot move to another sector. They have to continue producing haircuts. In equilibrium, the international price of haircut and their wage have to fall so as to maintain full employment in that sector.

Because of imperfect labor mobility, one has to distinguish between two types of reforms: an ex-ante liberalization is announced prior to the individual's occupational choice. An ex-post liberalization takes place after this choice, which therefore has taken place on the basis of a less liberal expected trade regimes.

These assumptions allow us to derive a number of interesting results regarding the effects of trade reform. We first find that the effect of liberalization on the terms of trade tend to favor the East. Second, under ex-post liberalization, there indeed exists a class of workers in the West who are harmed because they face competition from Eastern workers and cannot relocate to other activities. But we argue that if the East's economy is relatively small, their wage losses are not very large. Things are different, however, if there exist asymmetries in labor market institutions, such that upon reform, labor can relocate in the East but not in the West. Some workers in the West can then experience very large wage losses, more or less equal to the average wage gap between the two countries. Furthermore, the country as a whole may have net losses, which is implausible under ex-ante liberalization and, as I show, impossible under ex-post liberalization when labor is immobile in both countries. In such a case producers of non traded goods lose as well.

Thus, rigid labor markets in the West magnify opposition to reform there, and the worst case for the West is when the East is not rigid. ${ }^{4}$ The model is also used to derive interesting predictions about the distribution of gains and losses in the East.

\footnotetext{
${ }^{4}$ In the case of offshoring to India from the US, one is in the configuration where labor markets are more regulated in the East than in the West. The model can easily be used to deal with this case, and we expect the phenomenon to be supported in the West because of gains from trade.
} 


\section{What does the literature say?}

In this section, I discuss how this paper is connected to the existing literature on the effects of trade liberalization. Clearly, the literature has already analyzed the positive and normative implications of imperfect labor mobility, and this paper shares with it the basic insight that factors in import-competing sectors lose more if they cannot relocate. Its contribution is four-fold: (i) the use of the DFS model with a continuum of goods, in conjunction with segmented labor markets to analyze the impact of liberalization; (ii) considering an extension of the range of goods that are tradeable rather than a reduction in tariffs, which matches some real-world policy reforms and is much more tractable under the DFS model than under models with a finite, discrete number of goods; (iii) focusing on the case where liberalization takes place at the margin of the tradeable good where one country has the biggest comparative advantage - although the model could easily be used to study alternative configurations; and (iv) analyzing the implications of differential labor market institutions across blocks.

The modelling apparatus used here is based on Dornbusch et al. (1977). These authors do not consider labor market segmentation, and do not perform a detailed analysis of gains from trade in utility terms, limiting themselves to relative wages. They consider the role of uniform tariffs, which endogenously generate a band of non-traded goods around the critical one where comparative advantage is the same across countries. DFS find effects of liberalization on the terms of trade that are quite different from the ones studied here, and because of their assumption of perfect labor mobility, gains (or losses) are uniformly distributed within a country.

Leamer (1980), dealing with a variety of models, considers a timing similar to mine, i.e. a first period with mobile factors and a second period with costly mobility. ${ }^{5}$ As in the present paper, excessively fast liberalization may (absent compensatory transfers) harm workers in "exposed" industries, who must either

\footnotetext{
${ }^{5}$ Grossman (1983), analyzes the consequences of imperfect capital mobility.
} 
pay the adjustment costs or suffer a real wage loss. This defines a maximum pace of liberalization if one wants to buy the support of these workers. The analysis is carried in the context of a small open economy, so that there are aggregate gains from trade even though factor mobility is costly. However, Leamer also considers the impact of expected liberalization in period II on occupational choice in period I. In this second best world where tariffs in period I are exogenously given, less than full liberalization may then be optimal if that impact is taken into account, even if distributional issues are absent. ${ }^{6}$

Building on this work, Feenstra and Lewis (1994) consider how Pareto gains from trade can be implemented when labor is imperfectly mobile. They show that the traditional Dixit-Norman (1980) scheme of commodity taxation must be supplemented with "adjustment assistance", i.e. a subsidy for labor to move. ${ }^{7}$

Relative to this work, I do not consider the role of adjustment assistance. Instead, distributive consequences among various categories of workers, depending on their initial occupation, are analyzed in a richer fashion, as are terms-of-trade effects, that are absent in these papers' small open economy approach.

Furusawa and Lai (1999) also consider optimal tariff reduction when labor reallocation between sectors is costly. There are only two traded goods, an importable and an exportable, a non traded (numéraire good), and two skill levels. The unskilled can only work in importables or in the numéraire. Following a fall in tariffs, they must reallocate from the importables to the numéraire. If labor reallocation is costly, then optimal liberalization is gradual when these costs are convex but not when they are linear; gradualism may prevail in that case too, however, if there are commitment problems for each country to enforce the

\footnotetext{
${ }^{6}$ The linkage between expectations of future policies and current determination of a state variable by private agents makes this problem similar to a credibility problem à la KydlandPrescott (1977) and Barro-Gordon (1982). For an application to excess protection under imperfect labor mobility, see Staiger and Tabellini (1987).

${ }^{7}$ Adjustment assistance is also justified under rigidities different from costly mobility. Brecher and Chroudri (1994), for example, consider the case of involuntary unemployment generated by efficiency wages. Brander and Spencer (1994) analyze the distortionary effects of adjustement assistance, arguing that Pareto gains from trade may be infeasible if such distortions are large.
} 
agreement. These authors do not consider intra-country distributional issues, or asymmetries in labor market institutions. On the other hand, their model allows them to deal with dynamic game-theoretic aspects of liberalization in a tractable way.

While we do not consider optimal liberalization here, note that partial reform may be of lower value when dealing with the range of goods that are tradeable rather than with a uniform tariff level on all tradeables (or importables). As we show below, producers of the newly traded goods in the West lose from liberalization but producers of existing traded goods gain. Therefore, hairdressers lose less if a broad range of goods are liberalized than if just haircuts are liberalized. That stands in contrast to the literature just reviewed.

Another strand of literature asks whether trade liberalization may be harmful to one country, by relying on its effects on technology, rather than labor segmentation. For example, Samuelson (2004) argues that if the South becomes more productive in goods where the North has a comparative advantage, then the North is hurt as its terms-of-trade deteriorate. ${ }^{8}$ In the present model, a similar terms-of-trade effect arises, and we can show that the West may be harmed by liberalization even under perfect labor mobility. That is however for a different reason, namely that the East has a greater comparative advantage in newly traded goods than in existing traded goods. The effect emphasized by Samuelson arises, in some sense, endogenously, in that the East stops producing goods where it had a marginal comparative advantage. As these goods are now produced by the West, East's productivity in the goods exported by the West goes up on average, because of a composition effect: East is more productive in goods newly produced by the West than in its previous exports.

\footnotetext{
${ }^{8}$ See also Bhagwati et al. (2004) for a response.
} 


\section{Model}

There is a continuum of goods, indexed by $i \in[0,1]$. There are two countries, West and East. Variables pertaining to the East country are denoted by a star. Labor is the only factor of production. In the West, the production function for good $i$ is $y(i)=l(i)$, where $l(i)$ is the amount of labor used to produce $y(i)$ units of good $i$. In the East, the production function is $y^{*}(i)=l^{*}(i) / a(i)$, where $a(i)$ is a non-decreasing, differentiable function of $i$. We will concentrate on the case where $a(i) \geq 1$. Hence the West is more productive than the East, and more so, the higher the index $i$. One interpretation is that the East is less technologically advanced and that goods with a higher index $i$ are more "sophisticated". But it is just an interpretation and no result hinges on the absolute value of $a($.$) .$

Consumers in each country derive the following utility from consumption:

$$
U=\int_{0}^{1} \ln c(i) d i
$$

where $c(i)$ is consumption of good $i$. Accordingly, demand for good $i$ is given by $R / p(i)$, where $p(i)$ is the price of the good and $R$ is the consumer's income.

We assume that there exists $i_{T}$ such that a good $i$ is traded if and only if $i \geq i_{T}$. Thus, more sophisticated goods are more likely to be traded. This can be interpreted as reflecting the greater tradeability of manufactures relative to services.

Consequently, demand for good $i$ is

$-Y / p(i)$ in the West and $Y^{*} / p(i)^{*}$ in the East if the good is non traded. Here, $Y\left(\right.$ resp. $\left.Y^{*}\right)$ is the West's (resp. East's) GNP level, and $p(i)$ (resp. $p^{*}(i)$ ) is the price of good $i$ in the West (resp. East).

$-\left(Y+Y^{*}\right) / p(i)$ if the good is traded, where $p(i)=p^{*}(i)$ is now the international price of good $i$.

The labor market operates in two stages. In the first stage, people have to decide which sector they will work in, i.e. which good they will produce. They base their decision on their expectations for the value of $i_{T}$ that will prevail. In 
the second stage, labor supply committed to each good, and the labor market clears for each of these segments, yielding an equilibrium wage $w(i)$ in the West and $w^{*}(i)$ in the East for each segment.

\section{Ex-post equilibrium}

It is easy to compute the equilibrium once labor supply is frozen for each good.

In the West, the supply of labor in sector $i$ is equal to $l(i)$. In the East, it is equal to $l^{*}(i)$. Competition between firms implies that $p(i)=w(i)$ in the West, and $p^{*}(i)=w^{*}(i) a(i)$ in the East. Full employment of labor implies an inelastic supply of good $i$ equal to $y(i)=l(i)$ in the West and $y^{*}(i)=l^{*}(i) / a(i)$ in the East. Therefore, the sector-specific wage in the West is equal to

$$
\begin{aligned}
& w(i)=p(i)=\frac{Y}{l(i)} \text { if } i<i_{T} ; \\
& w(i)=p(i)=\frac{Y+Y^{*}}{l(i)+l^{*}(i) / a(i)} \text { if } i \geq i_{T} .
\end{aligned}
$$

Similarly, in the East,

$$
\begin{aligned}
& w^{*}(i)=\frac{p^{*}(i)}{a(i)}=\frac{Y^{*}}{l^{*}(i)} \text { if } i<i_{T} \\
& w^{*}(i)=\frac{p(i)}{a(i)}=\frac{Y+Y^{*}}{a(i) l(i)+l^{*}(i)} \text { if } i \geq i_{T} .
\end{aligned}
$$

To close the model, one needs to compute the GNP (=GDP) levels $Y$ and $Y^{*}$. One has to choose a price normalization, which gives one degree of freedom. We normalize Western GDP to 1 . Thus $Y=1$. To compute $Y^{*}$, just add all incomes in, say, the West to define its GDP:

$$
Y=1=\int_{0}^{i_{T}} Y / l(i) . l(i) d i+\int_{i_{T}}^{1} \frac{Y+Y^{*}}{l(i)+l^{*}(i) / a(i)} l(i) d i,
$$

or equivalently 


$$
Y^{*}=\frac{\int_{i_{T}}^{1} \frac{l^{*}(i)}{a(i) l(i)+l^{*}(i)} d i}{\int_{i_{T}}^{1} \frac{l(i)}{l(i)+l^{*}(i) / a(i)} d i} .
$$

The preceding formulas characterize the ex-post equilibrium conditional on the sector-specific labor supplies $l(i)$ and $l^{*}(i)$, irrespective of whether these supplies were determined on the basis of the actual realization of $i_{T}$ vs. some other expected value.

\section{$5 \quad$ Ex-ante equilibrium}

Let us now characterize the equilibrium allocation of labor when the actual level of trade $i_{T}$ is equal to the expected one. The total workforce is equal to $L$ in the West and $L^{*}$ in the East. In the first period, workers freely choose which sectors to work in. It follows that, in each country, the wage must be the same for all sectors with a positive labor force. Furthermore, in the other sectors, a firm employing some workers at that wage should not be able to make any profits. If its profits were strictly negative, then the good can only be produced in the other country.

Consequently, in all non traded sectors, the wage must be the same. Using the normalization $Y=1$ and the demand curves defined in section 3, we get that

$$
\begin{aligned}
w(i) & =w=\frac{1}{\bar{l}}, i<i_{T} ; \\
w^{*}(i) & =w^{*}=\frac{Y^{*}}{\bar{l}^{*}}, i<i_{T} .
\end{aligned}
$$

In these formulas, $\bar{l}$ is the (endogenous) common employment level for all the non traded sectors, and $\bar{l}^{*}$ is its counterpart in the East. Turning now to the traded goods sectors, we see that there are three possibilities:

A. The good will only be produced in the West. In this case one must have $l(i)>0$ and $w(i)=w=p(i)$, implying, using (4) and (1), that $l(i)=\bar{l}\left(1+Y^{*}\right)$. 
This defines the employment level common to all traded goods only produced in the West. Furthermore, the price of these goods cannot exceed its unit cost in the East, implying $w \leq a(i) w^{*}$. Thus there exists a critical level of sophistication $i_{C}$ such that

$$
a\left(i_{C}\right)=w / w^{*}
$$

All goods such that $i>i_{C}$ are entirely produced in the West.

B. The good will only be produced in the East. Here we get $l(i)=0$, $w^{*}(i)=w^{*}$, so that, given $(2), l^{*}(i)=\left(1+Y^{*}\right) / w^{*}=\bar{l}^{*}\left(1+Y^{*}\right) / Y^{*}$. Goods such that $i<i_{C}$ can only be produced in the East.

C. Therefore, only the critical good $i_{C}$ can be produced in both countries, which defines a set of measure zero.

To close the model, we have to compute the employment levels in non-traded goods $\bar{l}$ and $\bar{l}^{*}$ and the GDP level in the East $Y^{*}$. Equality of supply and demand in the labor market for each country allows to easily compute $\bar{l}$ and $\bar{l}^{*}$ :

$$
\begin{aligned}
\bar{l} i_{T}+\bar{l}\left(1+Y^{*}\right)\left(1-i_{C}\right) & =L ; \\
\bar{l}^{*} i_{T}+\bar{l}^{*} \frac{1+Y^{*}}{Y^{*}}\left(i_{C}-i_{T}\right) & =L^{*} .
\end{aligned}
$$

Finally, equation (3) implies

$$
Y^{*}=\frac{i_{C}-i_{T}}{1-i_{C}}
$$

Substituting into (7) and (8) we get

$$
\bar{l}=L ; \bar{l}^{*}=L^{*} .
$$

Therefore,

$$
\begin{aligned}
w & =\frac{1}{L} ; \\
w^{*} & =\frac{i_{C}-i_{T}}{\left(1-i_{C}\right) L^{*}}
\end{aligned}
$$


Using these along with (4)-(5) into (6), we get a formula determining $i_{C}$ :

$$
a\left(i_{C}\right)=\frac{L^{*}\left(1-i_{C}\right)}{L\left(i_{C}-i_{T}\right)}
$$

\section{Ex-ante trade liberalization}

It is instructive to check whether both countries gain from trade liberalization if it is announced ex-ante, that is when people can adjust their occupational choice-or, equivalently, when labor markets are not segmented. Standard small open economy results do not apply and in principle one of the two countries may lose because of terms-of-trade effects.

In this model, trade liberalization is a reduction in $i_{T}$, i.e. a widening of the range of goods that can be traded. An important aspect, which is clearly due to our assumptions, is that the West has a comparative disadvantage in the new traded goods. The opposite would be true if we had assumed that the traded goods were at the bottom, instead of the top, of the sophistication ranking. (One could also consider the case of an interior interval of traded-goods, which would generate two potential reforms: one where the new traded goods are less sophisticated, and another were they are more sophisticated.)

Under such an "ex-ante" liberalization, one just has to apply the preceding analysis and compute the derivative of utility with respect to $i_{T}$.

In the West, the nominal wage rate is independent of $i_{T}$. The change in welfare is just the opposite of the change in the consumer price index. The internal price of all goods produced by the West is $p(i)=w=1 / L$. The price of an imported good is $p(i)=a(i) w^{*}=a(i) w / a\left(i_{C}\right)=\frac{a(i)}{L a\left(i_{C}\right)}$. The consumer price index $p$ is therefore given by

$$
\begin{aligned}
\ln p & =\left(\ln \frac{1}{L}\right)\left(i_{T}+1-i_{C}\right)+\int_{i_{T}}^{i_{C}} \ln \frac{a(i)}{L a\left(i_{C}\right)} d i \\
& =\ln \frac{1}{L}+\int_{i_{T}}^{i_{C}} \ln \frac{a(i)}{a\left(i_{C}\right)} d i .
\end{aligned}
$$

This formula implies that any dose of free trade is preferable to full autarky, 
i.e. to $i_{T}=i_{C}=1$, since in that case one has $\ln p=\ln \frac{1}{L}>\ln \frac{1}{L}+\int_{i_{T}}^{i_{C}} \ln \frac{a(i)}{a\left(i_{C}\right)} d i$. However, that does not tell us whether the West gains from liberalization once some trade exists.

Differentiating (12) with respect to $i_{T}$, we get

$$
\frac{d \ln p}{d i_{T}}=-\ln \frac{a\left(i_{T}\right)}{a\left(i_{C}\right)}-\frac{a^{\prime}\left(i_{C}\right)}{a\left(i_{C}\right)}\left(i_{C}-i_{T}\right) \frac{d i_{C}}{d i_{T}}
$$

Differentiating (11) we get

$$
\frac{d i_{C}}{d i_{T}}=\frac{1}{\left(i_{C}-i_{T}\right) \frac{a^{\prime}\left(i_{C}\right)}{a\left(i_{C}\right)}+\frac{1-i_{T}}{1-i_{C}}}>0 .
$$

Not surprisingly, trade liberalization implies a fall in $i_{C}$; while producers of the new traded goods in the West must relocate to another activity, as the West has no comparative advantage in these goods, the West takes over the most sophisticated goods produced by the East, triggering a similar labor displacement there.

Substituting (14) into (13), we get

$$
\frac{d \ln p}{d i_{T}}=-\ln \frac{a\left(i_{T}\right)}{a\left(i_{C}\right)}-\frac{\frac{a^{\prime}\left(i_{C}\right)}{a\left(i_{C}\right)}\left(i_{C}-i_{T}\right)}{\left(i_{C}-i_{T}\right) \frac{a^{\prime}\left(i_{C}\right)}{a\left(i_{C}\right)}+\frac{1-i_{T}}{1-i_{C}}} \lessgtr 0 .
$$

This expression is not necessarily positive: the West may lose from liberalization. While it imports new goods that are more efficiently imported than produced at home (the first term), the East is more productive in the newly traded goods than in the other traded goods; this pushes up its wage and the terms of trade improve in its favor ${ }^{9}$. Consequently, the existing set of imported goods is more expensive, which harms the West. That effect is captured by the second term in (15). In principle, if $\frac{a^{\prime}\left(i_{C}\right)}{a\left(i_{C}\right)}$ is large enough, this term may dominate and the West may lose on net. However, that does not seem very likely,

${ }^{9}$ Similar effects arise in Itoh and Kiyono (1987). 
since a first order approximation - which is more accurate, the more linear is the $\ln a()$ function - yields

$$
-\ln \frac{a\left(i_{T}\right)}{a\left(i_{C}\right)} \approx \frac{a^{\prime}\left(i_{C}\right)}{a\left(i_{C}\right)}\left(i_{C}-i_{T}\right)>\frac{\frac{a^{\prime}\left(i_{C}\right)}{a\left(i_{C}\right)}\left(i_{C}-i_{T}\right)}{\left(i_{C}-i_{T}\right) \frac{a^{\prime}\left(i_{C}\right)}{a\left(i_{C}\right)}+\frac{1-i_{T}}{1-i_{C}}} .
$$

Furthermore, the reason why the West may lose, i.e. that its imports get more expensive, is quite remote from the usual complaints about liberalization displacing jobs. ${ }^{10}$

As far as the East is concerned, the terms of trade effect goes in the same direction as the direct effect: The East unambiguously gains from reform. To check that, note that the price of good $i$ in the East is $p^{*}(i)=a(i) w^{*}=$ $a(i) /\left(L a\left(i_{C}\right)\right)$ for $i<i_{C}$, and $p^{*}(i)=p(i)=w=1 / L$ for $i>i_{C}$. Therefore, the price level in the East is

$$
\ln p^{*}=\int_{0}^{i_{C}} \ln \left(a(i) w^{*}\right) d i+\left(1-i_{C}\right) \ln \left(\frac{1}{L}\right)
$$

The real consumption wage is therefore equal to

$$
\begin{aligned}
\ln w^{*}-\ln p^{*} & =\left(1-i_{C}\right)\left(\ln w^{*}-\ln \frac{1}{L}\right)-\int_{0}^{i_{C}} \ln (a(i)) d i \\
& =-\left(1-i_{C}\right)\left(\ln a\left(i_{C}\right)\right)-\int_{0}^{i_{C}} \ln (a(i)) d i
\end{aligned}
$$

where (6) and (10) have been used.

Differentiating, we see that

$$
\frac{d\left(\ln w^{*}-\ln p^{*}\right)}{d i_{T}}=\frac{d i_{C}}{d i_{T}} \times\left(-\left(1-i_{C}\right) \frac{a^{\prime}\left(i_{C}\right)}{a\left(i_{C}\right)}\right)<0 .
$$

Thus the East unambiguously gains from a reduction in $i_{T}$.

This section's findings are summarized in the following proposition.

\footnotetext{
${ }^{10}$ DFS (1977) consider a rather different setting, where there are uniform tariffs across goods. This yields a range of non traded goods centered around the critical one $y^{*}$,rather than at the extreme of the distribution of comparative advantage as studied here. As a result, the terms-of-trade effects that they obtain are quite different, and nil if countries are of equal size-in this latter case the usual gains-from-trade result applies.
} 
PROPOSITION 1 - If liberalization is anticipated and/or there is free mobility between sectors, then upon liberalization

(i) GDP goes up in the East relative to the West;

(ii) all workers in the East gain;

(iii) workers in the West may either gain or lose, due to a deterioration in the terms of trade;

(iv) the West gains if the curvature of the $\ln a()$ function is not too strong.

\section{$7 \quad$ Ex-post trade liberalization}

I now analyze the impact of trade liberalization, under segmented labor markets, when it has not been expected by the agents when making their occupational choice. I assume that $l(i)$ and $l^{*}(i)$ are consistent with an ex-ante equilibrium for a trade level equal to $i_{T}$, but that the actual level that prevails is $\tilde{\imath}_{T}<$ $i_{T}$. Therefore $l(i)$ and $l^{*}(i)$ are determined as in Section 5, while remaining variables are determined as in Section 4 , with $i_{T}$ replaced by $\tilde{\imath}_{T}$. At the time of liberalization, the economy starts in a situation where the allocation of labor is as follows:

1. $l(i)=L, l^{*}(i)=L^{*}$ for $i<i_{T}$.

2. $l(i)=\frac{1-i_{T}}{1-i_{C}} L, l^{*}(i)=0$, for $i>i_{C}$

3. $l(i)=0, l^{*}(i)=\frac{1-i_{T}}{i_{C}-i_{T}} L^{*}$, for $i_{T}<i<i_{C}$.

Here, $i_{C}$ denotes the critical value of $i$ that prevails if liberalization does not take place, i.e. the solution to (11).

To compute how trade liberalization affects wages, we just have to mechanically apply the results of Section 4. Normalizing the West's GDP to 1 and denoting by $\tilde{Y}$ the East's GDP under liberalization, we get that 


$$
\begin{aligned}
\tilde{w}(i) & =\frac{1}{L}, i<\tilde{\imath}_{T} ; \\
\tilde{w}(i) & =\frac{1+\tilde{Y}^{*}}{L+L^{*} / a(i)}, \tilde{\imath}_{T}<i<i_{T} \\
\tilde{w}(i) & =\frac{1+\tilde{Y}^{*}}{L} \frac{1-i_{C}}{1-i_{T}}, i>i_{C} .
\end{aligned}
$$

Similarly, for the East we have

$$
\begin{aligned}
\tilde{w}^{*}(i) & =\frac{\tilde{Y}^{*}}{L^{*}}, i<\tilde{\imath}_{T} ; \\
\tilde{w}^{*}(i) & =\frac{1+\tilde{Y}^{*}}{a(i) L+L^{*}}, \tilde{\imath}_{T}<i<i_{T} \\
\tilde{w}^{*}(i) & =\frac{1+\tilde{Y}^{*}}{L^{*}} \frac{i_{C}-i_{T}}{1-i_{T}}, i_{C}<i<i_{T} .
\end{aligned}
$$

Finally, equation (3) allows to compute the East's GDP:

$$
\tilde{Y}^{*}=\frac{i_{C}-\tilde{\imath}_{T}-L \int_{\tilde{i}_{T}}^{i_{T}} \frac{1}{L+L^{*} / a(i)} d i}{1-i_{C}+L \int_{\tilde{\imath}_{T}}^{i_{T}} \frac{1}{L+L^{*} / a(i)} d i}
$$

These formulas allow to compute the distributive effects of liberalization. To do so, we must distinguish between six groups of people:

DEFINITION 1 - A worker in the West (resp. the East) belongs to -group $A$ (resp. group $A^{*}$ ) if he works in sector $i$ such that $i \geq i_{C}$ (resp. $\left.i_{T} \leq i \leq i_{C}\right)$;

-group $B$ (resp. group $B^{*}$ ) if $\tilde{\imath}_{T} \leq i<i_{T}$;

-group $C$ (resp. group $C^{*}$ ) if $i<\tilde{\imath}_{T}$.

Thus, A refers to producers of goods that were traded absent liberalization, B to workers who produce the newly traded goods, and C to the goods that remain non traded. 


\subsection{Distributive impact of a marginal liberalization}

The effects of liberalization may differ between workers, because labor cannot relocate upon liberalization. To simplify the analysis, I now confine myself to the case of a marginal liberalization, i.e. $\tilde{\imath}_{T}=i_{T}+d \tilde{\imath}_{T}$, where $d \tilde{\imath}_{T}<0$ is infinitesimal. In the next subsection, I establish some results about nonmarginal liberalizations.

A first point to be noted is that, as in the case of ex-ante liberalization, the East enjoys an improvement in its terms of trade. This is again because its relative productivity is higher in the new traded goods, compared to the existing ones. This improvement in the terms of trade is associated with an increase in its relative GDP $Y^{*}$. To see this, just differentiate (17) with respect to $\tilde{\imath}_{T}$ at $\tilde{\imath}_{T}=i_{T}$, making use of (11). We get

$$
\frac{d \tilde{Y}^{*}}{d \tilde{\imath}_{T}}=\frac{L^{*}}{\left(1-i_{C}\right)\left(L a\left(i_{T}\right)+L^{*}\right)}\left(\frac{a\left(i_{T}\right)}{a\left(i_{C}\right)}-1\right)<0 .
$$

Thus, a fall in $i_{T}$ unambiguously raises nominal (=relative) GDP in the East. From there it is straightforward to use (16) and compute the effects of liberalization on relative wages in the West. Group C's wage remains constant in nominal terms. They will be used as our benchmark group. Because $\tilde{Y}^{*}$ goes up, the wage of group A's workers goes up in nominal terms. Therefore, they get better-off relative to group C. Because they export to the East, they benefit from its relative growth, which raises demand for these goods and thus their equilibrium wage. Finally, producers of the newly traded goods in the West (group B) unambiguously lose in terms of wages. Their nominal wage falls from $1 / L$ to

$$
\begin{aligned}
\tilde{w}\left(i_{T}\right) & =\frac{1+\tilde{Y}^{*}}{L+L^{*} / a\left(i_{T}\right)} \\
& \approx \frac{1+Y^{*}}{L+L^{*} / a\left(i_{T}\right)} \\
& =\frac{a\left(i_{T}\right)}{L a\left(i_{C}\right)} \frac{a\left(i_{C}\right) L+L^{*}}{a\left(i_{T}\right) L+L^{*}}<1 / L .
\end{aligned}
$$


This wage loss is discrete, while the gains to other workers are infinitesimal (but the mass of workers who suffer that loss is infinitesimal). Therefore, given that the aggregate price level moves infinitesimally, group B loses not only relative to others but also in absolute terms.

The model is useful to perform back-of-the envelope calculations on the effects of trade liberalization on group B. Let us use the European case as a benchmark for our orders of magnitude. Suppose that the East's workforce is about $20 \%$ of that of the West, and that wages there are about one third of the West's. According to (6) one must then have $a\left(i_{C}\right)=3$; Eastern workers must be at least three times less productive than Western ones, in all goods exported by the West. Assume, to pick up the worst possible case, that the Polish "hairdressers", i.e. Eastern producers of the newly traded goods, have a productivity almost equal to Western ones, that is, $a\left(i_{T}\right) \approx 1$. Let us normalize $L$ to 1 , implying $L^{*}=0.2$. Then group B's wage absent liberalization is $w\left(i_{T}\right)=$ $1 / L=1$. Their new wage is

$$
\tilde{w}\left(i_{T}\right)=\frac{a\left(i_{T}\right)}{L a\left(i_{C}\right)} \frac{a\left(i_{C}\right) L+L^{*}}{a\left(i_{T}\right) L+L^{*}}=\frac{1}{3} \times \frac{3.2}{1.2}=0.89
$$

Thus liberalization of trade entails a wage loss of $11 \%$ for group B. That is by no means negligible, but not large. It is certainly much below the average level of payroll taxes in Europe, and one can think of many less controversial policy shifts that generate similar or larger losses for specific groups.

To compute the absolute gains to the two other groups of workers, we need to know how the price level in the West evolves. It is given by

$$
\begin{aligned}
\ln \tilde{p}= & \int_{0}^{i_{T}} \ln \tilde{w}(i) d i+\int_{i_{T}}^{i_{C}} \ln \left(a(i) \tilde{w}^{*}(i)\right) d i+\int_{i_{C}}^{1} \ln \tilde{w}(i) d i \\
= & \int_{0}^{\tilde{T}_{T}} \ln \frac{1}{L}+\int_{\tilde{\tau}_{T}}^{i_{T}} \ln \frac{1+\tilde{Y}^{*}}{L+L^{*} / a(i)} d i \\
& +\int_{i_{T}}^{i_{C}} \ln \left(\frac{\left(1+\tilde{Y}^{*}\right) a(i)}{L^{*}} \frac{i_{C}-i_{T}}{1-i_{T}}\right) d i+\int_{i_{C}}^{1} \ln \left(\frac{1+\tilde{Y}^{*}}{L} \frac{1-i_{C}}{1-i_{T}}\right) d i .
\end{aligned}
$$

We can use that formula to compute the effect of a marginal liberalization 
from $i_{T}$ to $\tilde{\imath}_{T}=i_{T}+d \tilde{\imath}_{T}<i_{T}$ :

$$
d \ln \tilde{p}=\left(1-i_{T}\right) \frac{d \tilde{Y}^{*}}{1+Y^{*}}-d \tilde{\imath}_{T}\left(\ln \frac{1+Y^{*}}{L+L^{*} / a\left(i_{T}\right)}-\ln \frac{1}{L}\right)
$$

As in the case of ex-ante liberalization, there is an efficiency effect and a terms of trade effect. The terms of trade effect is the first term, which represents the increment in the price level due to wage increases in the East. These increases also push up wages for producers of traded goods in the West, who are sheltered from competition from other workers. This effect is also reflected in that term, which is multiplicative in $\left(1-i_{T}\right)$, the total mass of traded goods ${ }^{11}$. The efficiency effect is the last term, which is equal to the range of liberalization $-d \tilde{\imath}_{T}$ times the price fall in the newly traded goods; this price fall is exactly equal to the wage loss of the corresponding workers: thus the more group B suffers from liberalization, the greater the efficiency gains from it.

If $d \ln \tilde{p} / d \tilde{\imath}_{T}>0$, then the West gains as a whole (since its nominal GDP is pinned down to 1), and group $\mathrm{C}$ also gains (since their wage is pinned down to $1 / L)$. Rearranging (20) by making use of (18),(11), and (9), we get that:

$$
\frac{d \ln \tilde{p}}{d \tilde{\imath}_{T}}=\left(\frac{z_{C}}{z_{T}}-1\right)-\ln \frac{z_{C}}{z_{T}},
$$

where $z_{C}=L+\frac{L^{*}}{a\left(i_{C}\right)}<z_{T}=L+\frac{L^{*}}{a\left(i_{T}\right)}$.

Because $x-1-\ln x \geq 0$ for all $x$, this expression is always positive. Thus there are always net gains from trade liberalization to the West in this case. That is paradoxical, because one could not show such a result in the case of ex-ante liberalization. Thus, labor immobility makes trade reform profitable for the country as a whole, while it might harm it if labor were mobile. The reason is that under ex-ante liberalization, wages in the East increase by more because labor relocates efficiently to the newly traded goods. Such reallocation is not

\footnotetext{
${ }^{11}$ The terms of trade effect in the case of ex-ante liberalization is only multiplicative in $\left(i_{C}-i_{T}\right)$, the mass of imported goods.
} 
possible under ex-post liberalization. ${ }^{12}$.

Since group A gains more than group C, it also gains.

To summarize:

PROPOSITION 2 - Consider an infinitesimal, unexpected drop of the trade margin $i_{T}$. Then its effect on workers in the West is as follows:

(i) Group B unambiguously loses, by a discrete amount.

(ii) Group A always gains.

(iii) Group C has a net positive gain which is always lower than that of group

A.

(iv) The country as a whole unambiguously gains.

Let us now turn to gainers and losers in the East. Again, we first look at nominal wages, which also gives us the distribution of income, and then compute the change in the nominal price level. We again have three groups: Producers of the existing traded goods (group $\mathrm{A}^{*}$ ), have a wage change equal to

$$
d \ln \tilde{w}^{*}(i)=\frac{d \tilde{Y}^{*}}{1+Y^{*}} .
$$

Producers of the newly traded goods (group B*) experience a discrete jump in wages:

$$
\begin{aligned}
\Delta \ln \tilde{w}^{*}(i) & =\ln \frac{1+Y^{*}}{a\left(i_{T}\right) L+L^{*}}-\ln \frac{Y^{*}}{L^{*}} \\
& =\ln \frac{a\left(i_{C}\right) L+L^{*}}{a\left(i_{T}\right) L+L^{*}}>0 .
\end{aligned}
$$

Because this wage jump is discrete, and because the price level moves only infinitesimally, these gains are real as well as nominal. We can perform similar back-of-the-envelope calculations as for group B. With $a\left(i_{C}\right)=3, a\left(i_{T}\right)=1, L=$ $1, L^{*}=0.2$, we get $\frac{a\left(i_{C}\right) L+L^{*}}{a\left(i_{T}\right) L+L^{*}}=\frac{3.2}{1.2}=2.67$. The wages of Eastern hairdressers

\footnotetext{
${ }^{12}$ That does not mean that net gains from trade are always larger when labor is immobile. The only thing we know is that they cannot be negative, while this possibility cannot be ruled out under ex-ante liberalization. It is difficult to say more. Even with a simple formulation like $a(i)=\exp (\alpha i)$, it is difficult to compare the two formulas.
} 
increase by a lot, since they have to converge to those of Western ones who are just as productive. As the Eastern workforce is just $20 \%$ of the Western one, most of the adjustment is in the form of a large increase in the Eastern hairdressers wage, with a moderate fall in the Western hairdressers wage.

Turning now to group $\mathrm{C}^{*}$, the producers of non traded goods, their nominal wage change is

$$
d \ln \tilde{w}^{*}(i)=\frac{d \tilde{Y}^{*}}{Y^{*}} .
$$

Their proportional (and therefore absolute, as ex-ante wages are the same) wage gain is therefore larger than that of group $A^{*}$. They benefit more from the (relative) increase in demand brought about by the East's improvement in the terms of trade, because they serve only the Eastern market.

Therefore, those who gain the least are group $\mathrm{A}^{*}$, and group $\mathrm{B}^{*}$ gains the most.

We can now compute the change in the price level and the real gains for groups $\mathrm{A}^{*}$ and $\mathrm{C}^{*}$. The consumer price level in the East is given by

$$
\begin{aligned}
\ln \tilde{p}^{*}= & \int_{0}^{i_{C}} \ln \left(a(i) \tilde{w}^{*}(i)\right) d i+\int_{i_{C}}^{1} \ln (\tilde{w}(i)) d i \\
= & \int_{0}^{\tilde{\imath}_{T}} \ln a(i) d i+\tilde{\imath}_{T} \ln \frac{\tilde{Y}^{*}}{L^{*}}+\int_{\tilde{\imath}_{T}}^{i_{T}} \ln \frac{1+\tilde{Y}^{*}}{L+L^{*} / a(i)} d i \\
& +\int_{i_{T}}^{i_{C}} \ln a(i) d i+\left(i_{C}-i_{T}\right) \ln \frac{\left(1+\tilde{Y}^{*}\right)\left(i_{C}-i_{T}\right)}{L^{*}\left(1-i_{T}\right)} \\
& +\left(1-i_{C}\right) \ln \frac{\left(1+\tilde{Y}^{*}\right)\left(1-i_{C}\right)}{L\left(1-i_{T}\right)} .
\end{aligned}
$$

Considering again a marginal liberalization, we get

$$
\begin{aligned}
\frac{d \ln \tilde{p}^{*}}{d \tilde{\imath}_{T}}\left(\tilde{\imath}_{T}=\right. & \left.i_{T}\right)=\ln \frac{a\left(i_{T}\right) Y^{*}}{L^{*}}-\ln \frac{1+Y^{*}}{L+L^{*} / a\left(i_{T}\right)} \\
& +\frac{d Y^{*}}{d \tilde{\imath}_{T}}\left[\frac{i_{T}}{Y^{*}}+\frac{1-i_{T}}{1+Y^{*}}\right] \\
= & \ln \frac{L a\left(i_{T}\right)+L^{*}}{L a\left(i_{C}\right)+L^{*}}+\frac{d Y^{*}}{d \tilde{\imath}_{T}}\left[\frac{i_{T}}{Y^{*}}+\frac{1-i_{T}}{1+Y^{*}}\right]<0,
\end{aligned}
$$


where (9) and (11) have been used.

In nominal terms, the price level unambiguously goes up upon reform. What happens to the living standards of groups $\mathrm{A}^{*}$ and $\mathrm{C}^{*}$ ? $\mathrm{A}^{*}$ clearly loses, since for this group we have

$$
\frac{d \ln \tilde{w}^{*}(i)}{d \tilde{\imath}_{T}}=\frac{d Y^{*}}{d \tilde{\imath}_{T}} \frac{1}{1+Y^{*}}>\frac{d \ln \tilde{p}^{*}}{d \tilde{\imath}_{T}} .
$$

Their wage increases as much as the price of the existing traded goods, and less than the price of the newly traded goods and the non-traded goods. Thus they unambiguously lose from the reform. Haircuts and taxi fares have become more expensive, and it is too late for them to become a hairdresser or a taxi driver.

Turning now to group $\mathrm{C}^{*}$, intuitively, it should gain: its nominal wage is proportional to nominal GDP; therefore it gains if and only if the country as a whole gains, which should be true, as its terms of trade improve. We can check that by computing the change in $\ln \tilde{w}^{*}(i) / \tilde{p}^{*}$ for these workers, using (9), (11) and (18):

$$
\begin{aligned}
\frac{d \ln \tilde{w}^{*}(i)}{d \tilde{\imath}_{T}}-\frac{d \ln \tilde{p}^{*}}{d \tilde{\imath}_{T}} & =-\ln \frac{L a\left(i_{T}\right)+L^{*}}{L a\left(i_{C}\right)+L^{*}}+\left(1-i_{T}\right) \frac{d Y^{*}}{d \tilde{\imath}_{T}}\left[\frac{1}{Y^{*}}-\frac{1}{1+Y^{*}}\right] \\
& =-\ln \frac{L a\left(i_{T}\right)+L^{*}}{L a\left(i_{C}\right)+L^{*}}+\frac{L\left(a\left(i_{T}\right)-a\left(i_{C}\right)\right)}{L a\left(i_{T}\right)+L^{*}}<0
\end{aligned}
$$

This expression is negative because it is equal to $\ln \frac{\hat{z}_{C}}{\hat{z}_{T}}+1-\frac{\hat{z}_{C}}{\hat{z}_{T}}$ for $\hat{z}_{C}=$ $L a\left(i_{C}\right)+L^{*}$ and $\hat{z}_{T}=L a\left(i_{T}\right)+L^{*}$. Thus reform unambiguously increases these workers' living standards.

To summarize:

PROPOSITION 3 - Consider an infinitesimal, unexpected drop in the trade margin $i_{T}$. Then its effect on workers in the East is as follows:

(i) Group $B^{*}$ unambiguously gains, by a discrete amount.

(ii) Group $A^{*}$ always loses.

(iii) Group $C^{*}$ has a net positive gain.

(iv) The country as a whole unambiguously gains. 


\subsection{Nonmarginal liberalization}

In the Appendix, I establish some results for a non marginal liberalization, limiting the analysis to the welfare of producers of newly traded goods in the West. They are summarized by the following proposition.

PROPOSITION 4-Consider a discrete, non anticipated fall of the trade margin from $i_{T}$ to $\tilde{\imath}_{T}$. Then in the West:

(i) For $i>\tilde{\imath}_{T}$ and $i-\tilde{\imath}_{T}$ small enough, workers in sector $i$ unambiguously lose.

(ii) Further liberalizations increase the welfare of producers of traded goods: $\forall i>\tilde{\imath}_{T}, \frac{d \ln (w(i) / p)}{d \tilde{\imath}_{T}}<0$

(iii) Exposed workers with a sufficient comparative advantage, i.e. such that (33) holds, may enjoy absolute gains from the reform.

\section{Asymmetric labor market institutions}

There are good reasons why it is costly to relocate from one activity to another: locating a suitable job opportunity, retraining, moving, etc.; however, in a number of countries, these barriers are regulatory rather than genuine: degree requirements, licences, numerus clausus, etc. Thus it is conceivable that one country has different mobility costs from the other. In this section, we consider what happens when labor in the East can freely relocate upon reform, while workers in the West are stuck in the industry they have chosen.

It is easy to see that in such a case, wages for producers of the newly traded goods in the West are going to fall by much more than in the previous section: in the East, as much labor as necessary will flow into these sectors so as to equate wages to those of the economy as a whole.

Let us characterize the effects of ex-post liberalization in this case.

It is more convenient now to start the analysis with the East. In that country, there is now a single wage $\tilde{w}^{*}$. Denoting by $\tilde{l}^{*}$ the new common employment 
level in non traded industries, and $\tilde{Y}^{*}$ the new GDP level, we have $\tilde{w}^{*}=\tilde{Y}^{*} / \tilde{l}^{*}$. In the newly traded goods $\left(i \in\left[\tilde{\imath}_{T}, i_{T}\right]\right)$ the employment level $\tilde{l}^{*}(i)$ adjusts to equate the wage in that sector to the economy's wage, implying that

$$
\frac{1+\tilde{Y}^{*}}{a(i) L+\tilde{l}^{*}(i)}=\tilde{w}^{*}=\frac{\tilde{Y}^{*}}{\tilde{l}^{*}}
$$

where the West's GDP is again normalized to one.

Equation (22) determines the employment level in the newly traded goods as a function of $\tilde{Y}^{*}$ and $\tilde{l}^{*}$ :

$$
\tilde{l}^{*}(i)=\frac{1+\tilde{Y}^{*}}{\tilde{Y}^{*}} \tilde{l}^{*}-a(i) L .
$$

For the existing traded goods that were produced in the East, in equilibrium it must continue to produce all of them, as no Western workers can move to those sectors. Employment adjusts again to equate wages to the economy-wide level:

$$
\frac{1+\tilde{Y}^{*}}{\tilde{l}^{*}(i)}=\tilde{w}^{*}=\frac{\tilde{Y}^{*}}{\tilde{l}^{*}}
$$

so that we have

$$
\tilde{l}^{*}(i)=\tilde{l}^{*} \frac{1+\tilde{Y}^{*}}{\tilde{Y}^{*}}
$$

Finally, Eastern workers may also in principle produce the goods that were exported by the West $\left(i>i_{C}\right)$. However, that is unlikely to be an equilibrium outcome, as its terms of trade are likely to improve, making it more expensive at the margin for the East to produce these goods: If labor were perfectly mobile in the West as well, we know that $i_{C}$ would fall, not rise. Hence we look for an equilibrium such that the East does not produce these goods. The wage earned by Western workers producing these goods is

$$
\begin{aligned}
\tilde{w}(i) & =\frac{1+\tilde{Y}^{*}}{l(i)} \\
& =\frac{1+\tilde{Y}^{*}}{L\left(1-i_{T}\right)}\left(1-i_{C}\right) .
\end{aligned}
$$


It is also equal to the good's international price $p(i)$.

Using these derivations, labor market equilibrium in the East implies that

$$
L^{*}=\tilde{\imath}_{T} \tilde{l}^{*}+\left(i_{C}-\imath_{T}\right) \tilde{l}^{*} \frac{1+\tilde{Y}^{*}}{\tilde{Y}^{*}}+\int_{\tilde{\imath}_{T}}^{i_{T}}\left(\frac{1+\tilde{Y}^{*}}{\tilde{Y}^{*}} \tilde{l}^{*}-a(i) L\right) d i
$$

which is equivalent to

$$
\tilde{l}^{*}=\frac{L^{*}+L \int_{\tilde{i}_{T}}^{i_{T}} a(i) d i}{\tilde{\imath}_{T}+\frac{1+\tilde{Y}^{*}}{\tilde{Y}^{*}}\left(i_{C}-\tilde{\imath}_{T}\right)} .
$$

Finally, we can again compute $\tilde{Y}^{*}$ by summing all incomes in the West:

$\tilde{Y}=1=\int_{0}^{\tilde{\imath}_{T}} 1 / L \cdot L d i+\int_{\tilde{\imath}_{T}}^{i_{T}} a(i) \frac{\tilde{Y}^{*}}{\tilde{l}^{*}} L d i+\int_{i_{C}}^{1} \frac{1+\tilde{Y}^{*}}{L\left(1-i_{T}\right) /\left(1-i_{C}\right)} \frac{L\left(1-i_{T}\right)}{\left(1-i_{C}\right)} d i$

which yields

$$
\tilde{Y}^{*}=\frac{i_{C}-\tilde{\imath}_{T}}{\frac{L}{l^{*}} \int_{\tilde{\imath}_{T}}^{i_{T}} a(i) d i+1-i_{C}} .
$$

The solution to (25) and (26) is

$$
\tilde{l}^{*}=L^{*}
$$

and

$$
\tilde{Y}^{*}=\frac{L^{*}\left(i_{C}-\tilde{\imath}_{T}\right)}{L \int_{\tilde{\imath}_{T}}^{i_{T}} a(i) d i+L^{*}\left(1-i_{C}\right)} .
$$

Differentiating (27) at $\tilde{\imath}_{T}=i_{T}$ we get, using (11):

$$
\frac{d \tilde{Y}^{*}}{d \tilde{\imath}_{T}}=\left(\frac{a\left(i_{T}\right)}{a\left(i_{C}\right)}-1\right) \frac{1}{1-i_{C}}
$$

Again, $d \tilde{Y}^{*} / d \tilde{\imath}_{T}<0$, reflecting the terms of trade improvements for the East brought about by liberalization. Furthermore, this quantity is larger in absolute value than that in (18), meaning that the East gets a higher improvement in its 
relative GDP than if labor were immobile there. That is not surprising, since labor reallocation increases total GDP by eliminating cross-sectoral differences in the marginal value product of labor.

It is also easy to check that the East as a whole gains, as do all workers there whose wages are equalized. The consumer price level is

$$
\begin{aligned}
\ln \tilde{p}^{*} & =\int_{0}^{i_{C}} \ln \left(a(i) \tilde{w}^{*}\right) d i+\int_{i_{C}}^{1}(\ln \tilde{w}(i)) d i \\
& =\int_{0}^{i_{C}} \ln \left(a(i) \tilde{w}^{*}\right) d i+\left(1-i_{C}\right) \ln \left[\frac{1+\tilde{Y}^{*}}{L \frac{1-i_{T}}{1-i_{C}}}\right] d i .
\end{aligned}
$$

Using this formula and (23), we see that a marginal trade liberalization around $\tilde{\imath}_{T} \approx i_{T}$ has an effect on $\tilde{p}_{c}^{*}$ given by

$$
\frac{d \ln \tilde{p}^{*}}{d \tilde{\imath}_{T}}\left(\tilde{\imath}_{T}=i_{T}\right)=\frac{d \tilde{Y}^{*}}{d \tilde{\imath}_{T}}\left[\frac{1}{Y^{*}} i_{C}+\frac{1-i_{C}}{1+Y^{*}}\right]
$$

which is both negative and greater than $\frac{d \ln \tilde{w}^{*}}{d \tilde{\imath}_{T}}=\frac{1}{Y^{*}} \frac{d \tilde{Y}^{*}}{d \tilde{\imath}_{T}}$. Consequently, $\frac{d \ln \tilde{w}^{*}}{d \tilde{\imath}_{T}}-$ $\frac{d \ln \tilde{p}^{*}}{d \bar{\imath} T}<0$. Liberalization unambiguously benefits the East's consumers. ${ }^{13} \mathrm{Al}-$ though it is not obvious to compare aggregate gains for the East with those computed in the previous section, one should clearly expect lower opposition to liberalization than if labor in the East were immobile, as we have seen that all producers of existing traded goods then lose. We again summarize the effects on the East's welfare with the following proposition:

PROPOSITION 5 - If labor is mobile in the East but not in the West, a marginal ex-post liberalization unambiguously benefits all workers in the East. Furthermore, its relative GDP increases by more than if labor were immobile in the East.

We now turn to the West. We again have three groups of workers, A,B, and $\mathrm{C}$, as defined above. We start with group B, workers in the newly traded goods.

\footnotetext{
${ }^{13}$ One would like to compare these consumer's gains to those they derive from ex-ante liberalization, i.e. if labor were freely mobile in the West as well. Unfortunately, the formulas suggest the comparison is ambiguous and yield no clear economic intuition for that.
} 
In these sectors, the wage in the West is equal to

$$
\tilde{w}(i)=a(i) \tilde{w}^{*}
$$

If $a(i)$ is close enough to one (as in the preceding numerical example), and if liberalization is only marginal, $\tilde{w}^{*}$ will differ from $w^{*}$ only infinitesimally, and $\tilde{w}(i)$ will fall to the Eastern wage level: French hairdressers then indeed lose two-thirds of their income. The inflow of Polish hairdressers, coming from other occupations, pushes them down their marginal revenue schedule, up to the point where they earn the Polish equilibrium wage. More precisely, their wage falls to

$$
\begin{aligned}
\tilde{w}\left(i_{T}\right) & =a\left(i_{T}\right) \tilde{w}^{*} \\
& \approx a\left(i_{T}\right) w^{*} \\
& =\frac{a\left(i_{T}\right)}{L a\left(i_{C}\right)},
\end{aligned}
$$

where equations (10) and (11) have been used. Clearly, the RHS of (29) is smaller than that of (19).

Turning now to group C, their wage is equal to $\tilde{w}(i)=\tilde{Y} / l(i)=1 / L$. It is again constant in nominal terms, and their gains are again the same as for the country as a whole. The price level is

$$
\ln \tilde{p}=\int_{0}^{\tilde{i}_{T}} \ln \frac{1}{L}+\int_{\tilde{\imath}_{T}}^{i_{C}} \ln \left(a(i) \tilde{w}^{*}\right)+\int_{i_{C}}^{1} \ln \frac{\left(1+\tilde{Y}^{*}\right)\left(1-i_{C}\right)}{L\left(1-i_{T}\right)} .
$$

which allows to compute the effect of marginal liberalization:

$$
\frac{d \ln \tilde{p}}{d \tilde{\imath}_{T}}=\ln \frac{a\left(i_{C}\right)}{a\left(i_{T}\right)}+\frac{d \tilde{Y}^{*}}{d \tilde{\imath}_{T}}\left[\frac{\left(i_{C}-i_{T}\right)}{Y^{*}}+\frac{1-i_{C}}{1+Y^{*}}\right],
$$

where we have made use of $\tilde{w}^{*}=\tilde{Y}^{*} / L^{*}$ and of $w^{*} / w=w^{*} L=a\left(i_{C}\right)$.

The first term is positive, reflecting the efficiency gains of trade reform; the second term is negative, reflecting the effect of the terms of trade. If $\frac{d \ln p}{d \hat{\imath}_{T}}>0$, then both group $\mathrm{C}$ and the country as a whole gain from liberalization.

Substituting (28) we get

$$
\frac{d \ln \tilde{p}}{d \tilde{\imath}_{T}}=\ln \frac{a\left(i_{C}\right)}{a\left(i_{T}\right)}+\left(\frac{a\left(i_{T}\right)}{a\left(i_{C}\right)}-1\right)\left[\frac{1-i_{C}}{1-i_{T}}+1\right] .
$$


This quantity may either be positive or negative, while $\frac{d \ln \tilde{p}}{d \tilde{\imath}_{T}}$ was always positive in the preceding subsection. Labor mobility in the East magnifies both the efficiency effects and the terms-of-trade effects of liberalization, and makes it possible that the latter dominates so that the country as a whole loses, which was ruled out when labor could not move in either country.

Finally, what happens to group A? Differentiating (24) and subtracting (30), and making use again of (28), we get

$$
\frac{d \ln \tilde{w}(i)}{d \tilde{\imath}_{T}}-\frac{d \ln \tilde{p}}{d \tilde{\imath}_{T}}=\frac{i_{C}}{1-i_{T}}\left(\frac{a\left(i_{T}\right)}{a\left(i_{C}\right)}-1\right)+\ln \frac{a\left(i_{T}\right)}{a\left(i_{C}\right)}+1-\frac{a\left(i_{T}\right)}{a\left(i_{C}\right)}<0 .
$$

Therefore, these workers unambiguously gain again. Furthermore, this quantity is larger in absolute value than that in (21); gains are larger than when labor in the East is immobile.

PROPOSITION 6 - If labor is mobile in the East but not in the West, upon ex-post marginal liberalization:

(i) Group C and the economy as a whole may either gain or lose,

(ii) The wage of group $B$ falls to the Eastern level; it loses by a discrete amount, which is larger than if labor in the East were immobile.

(iii) Group A unambiguously gains, by an infinitesimal amount which is larger than if labor in the East were immobile.

Hence the results are qualitatively similar to those of the previous section; but the discrete wage fall of Western "hairdressers" is much larger, and the producers of non traded goods (and the country as a whole) may now lose. The first face an inflow of Eastern hairdressers which is larger than if labor reallocation were impossible there. The second suffer from a stronger improvement in the East's terms of trade. On the other hand, producers of non traded goods gain more, since they export to the East and benefit from its greater relative GDP.

This discussion suggests that the case studied here - labor immobility in the West but not in the East - is the least favorable one for the West. At the aggregate level, losses are more plausible than under ex-ante liberalization, and 
were ruled out if labor could not move in the East. At the disaggregate level, it is the case where the gains from trade are most unevenly distributed in the West, with producers of existing traded goods getting a greater share than in the other two cases, and producers of newly traded goods experiencing a wage drop down to the Eastern level.

\section{Other extensions}

I have extended the model in two directions, in an Appendix available from the author upon request. First, the logarithmic utility function can be replaced by a more general CES one. Second, the model can be made more in line with an interpretation in terms of tradeable services, rather than tradeable goods, by assuming that exporters have to spend part of their income consuming in the other country.

The distributive effects highlighted above are basically robust to these extensions. However, some novel phenomena arise. For example, we show that the greater the share of income exporters have to spend in the other country, the lower the gains from liberalization to producers of non traded goods (groups $\mathrm{C}$ and $\mathrm{C}^{*}$ ) in both countries, and they may even lose.

\section{Conclusion}

Let us review our main findings and their implications:

1. There exists a terms-of-trade effect which favors the East. That is because (by assumption) the goods where the West's relative productivity is highest are already traded, which is not the case for the East. In principle, that effect may be strong enough to generate net losses from trade for the West even under perfect mobility, although the formulas above suggest it is unlikely.

2. If labor is immobile ex-post, there will be a constituency against reform in both countries. In the West, producers of the newly traded goods always lose. 
On the other hand, producers of non traded goods cannot lose, nor can the country as a whole. In the East, producers of traded goods, who face a higher price level at home, but can't relocate to the high value new traded goods, lose because the price of their own goods, which also reflects demand in the West, rises by less than the domestic consumer price level. If liberalization is marginal, few people lose a "large" amount in the West, while many people lose a "small amount" in the East.

3. The political economy consequences of these observations clearly depend on how different groups affect collective choices. If people simply vote, marginal liberalization will actually be met by more opposition in the East than in the West. But a number of alternative assumptions will yield the opposite conclusion. That will be the case if voters disregard small losses, and if groups who lose a large amount can organize to block the reform. It will also be true if, in the fashion of Gersbach and Schniewind (2001), voters have a better perception of direct effects of policy choices on their welfare, than of indirect effects. It is far easier for producers of newly traded goods in the West to realize that they lose than for producers of traded goods in the East to find out that the CPI will rise by more than their own wage.

4. Because producers of traded goods in the West gain from liberalization, the social groups who oppose a given reform will, once it is implemented, support further reforms. Another way to put it is that they will lose less, or even gain, if a broad range of goods, rather than a narrow one, becomes tradeable. While losses are smaller under a broader reform, the number of losers is clearly larger. Hence whether a broad reform is more politically viable than a narrow one depends on whether it is large groups, or small groups of agents with a strong motivation, that are most efficient in blocking a reform.

5. If labor is immobile in the West but not in the East, then workers there will all support liberalization, as they benefit both from a more efficient allocation of production and from an improvement in the terms of trade. As for the West, 
gains and losses are more unevenly distributed as compared to the case where labor is immobile in both countries. Producers of the newly traded goods lose much more, producers of traded goods gain more, and the country as a whole and producers of non traded goods may now lose. This is the configuration which is likely to generate the fiercest opposition from the West. In my view, this result sheds light on the casual observation that the EU countries that opposed the service directive, e.g. France, have a high level of labor market regulation, while the relatively deregulated countries, e.g. the UK, support the directive. 
Barro, R. and D. Gordon (1983), "A Positive Theory of Monetary Policy in a Natural Rate Model", Journal of Political Economy.

Bhagwati, Jagdish, Panagariya, Arvind, and Srinivasan, T. N., (2004) "The Muddles over Outsourcing", Journal of Economic Perspectives, 18,4, 93-114

Publication Date: Fall 2004

Brander, J. and B. Spencer (1994), "Trade adjustment assistance: Welfare and incentive effects of payments to displaced workers", Journal of International Economics, 36 (1994), 239-261

Brecher, R.A. and E. Choudhri (1994), "Pareto gains from trade, reconsidered: Compensating for jobs lost", Journal of International Economics, 36 (1994), 223-238

Cahuc, P. and F. Kramarz (2004), De la Précarité à la Mobilité : Vers une Sécurité Sociale Professionnelle, report to the French ministry of Finance.

Dixit, A. and V. Norman (1980), Theory of International Trade, James Nysbet, Welwyn, UK

Dornbusch, R., Fischer, S. and P. Samuelson (1977), "Comparative advantage, trade, and payments in a Ricardian model with a continuum of goods", American Economic Review

Feenstra, R.C. and T.R. Lewis (1994), "Trade adjustment assistance and Pareto gains from trade", Journal of International Economics, 36 (1994), 201222

Furusama, Taiji, and Edwin Lai (1999), "Adjustment costs and gradual trade liberalization", Journal of International Economics

Gersbach, H. and A. Schniewind (2001), "Awareness of General Equilibrium Effects and Unemployment", IZA Discussion paper \#394

Grossman, G. (1983), "Partially mobile capital: A general approach to twosector trade theory", Journal of International Economics, 15, 1/2, 1-17 
Helpman, E. and P. Krugman (1985), Market Structure and Foreign Trade, MIT Press

Itoh, Motoshige and Kazuharu Kiyono (1987), "Welfare-enhancing Export Subsidies", Journal of Political Economy 95, 1, 115-137

Kydland, F. and E. Prescott (1977), Rules rather than discretion: The

inconsistency of. optimal plans, Journal of Political Economy, 85, 473-490.

Leamer, E. (1980) "Welfare computations and the optimal staging of tariff reductions in models with adjustment costs", Journal of International Economics, $10,21-36$

Samuelson, Paul A. (2004), "Where Ricardo and Mill Rebut and Confirm Arguments of Mainstream Economists Supporting Globalization" Journal of Economic Perspectives, 18, 3, 135-46

Staiger, Robert, and Guido Tabellini (1987), "Discretionary trade policy and excessive protection", American Economic Review, 77, 5, 823-837. 


\section{APPENDIX - Proof of Proposition 4}

A first result that can be established is that the producers with the lowest comparative advantage $\left(i=\tilde{\imath}_{T}\right)$ always experience a discrete wage loss. To see this, note that their wage changes from $w=1 / L$ to $\tilde{w}(i)=\frac{1+\tilde{Y}^{*}}{L+L^{*} / a\left(\tilde{\imath}_{T}\right)}$. Using (17), we see that $\tilde{w}(i)<w$ if and only if

$$
L\left(1-\tilde{\imath}_{T}\right)<\left(L+L^{*} / a\left(\tilde{\imath}_{T}\right)\right)\left(1-i_{C}+L \int_{\tilde{\imath}_{T}}^{i_{T}} \frac{1}{L+L^{*} / a(i)} d i\right) .
$$

Since $\int_{\tilde{i}_{T}}^{i_{T}} \frac{1}{L+L^{*} / a(i)} d i>\frac{i_{T}-\tilde{\imath}_{T}}{L+L^{*} / a\left(\hat{i}_{T}\right)}$, a sufficient condition for (31) to hold is $L i_{T}+\frac{L^{*}}{a\left(\tilde{\tau}_{T}\right)}\left(1-i_{C}\right)-L i_{C}>0$. Using (11) to eliminate $i_{C}$, it is easy to check that this sufficient condition holds.

A second result is that conditional on being liberalized, producers of any good $i$ prefer full liberalization $\left(\tilde{\imath}_{T}=0\right)$ to take place. To see this, note again that their nominal wage is

$$
\tilde{w}(i)=\frac{1+\tilde{Y}^{*}}{L+L^{*} / a(i)} .
$$

It has to be deflated by the consumer price index, which can again be computed using the formulas for wages at the beginning of this section:

$$
\begin{aligned}
\ln \tilde{p}= & \int_{0}^{\tilde{\imath}_{T}} \ln \frac{1}{L} d j+\int_{\tilde{\imath}_{T}}^{i_{T}} \ln \frac{1+\tilde{Y}^{*}}{L+L^{*} / a(j)} d j \\
& +\int_{\imath_{T}}^{i_{C}} \ln \left[a(j) \frac{\left(1+\tilde{Y}^{*}\right)\left(i_{C}-i_{T}\right)}{L^{*}\left(1-i_{T}\right)}\right] d j \\
& +\int_{\imath_{C}}^{1} \ln \frac{\left(1+\tilde{Y}^{*}\right)\left(1-i_{C}\right)}{L\left(1-i_{T}\right)} d j .
\end{aligned}
$$

Subtracting, we get

$$
\begin{aligned}
\ln \tilde{w}(i)-\ln \tilde{p}= & \tilde{\imath}_{T}\left[\ln \left(1+\tilde{Y}^{*}\right)-\ln \frac{1}{L}\right]+\int_{\tilde{\imath}_{T}}^{i_{T}} \ln \left(L+L^{*} / a(j)\right) d j \\
& +K(i),
\end{aligned}
$$

where all the terms that do not depend on the degree of liberalization $\tilde{\imath}_{T}$ have 
been lumped in the constant $K(i)$. Differentiating with respect to $\tilde{\imath}_{T}$, we get

$$
\frac{d}{d \tilde{\imath}_{T}}(\ln \tilde{w}(i)-\ln \tilde{p})=\tilde{\imath}_{T} \frac{d \tilde{Y}^{*} / d \tilde{\imath}_{T}}{1+\tilde{Y}^{*}}+\ln \frac{L\left(1+\tilde{Y}^{*}\right)}{\left(L+L^{*} / a\left(\tilde{\imath}_{T}\right)\right)} .
$$

The last term is negative, as it is equal to the log wage change of workers in the $\tilde{\imath}_{T}$ sector. Furthermore, by differentiating the RHS of $(17)^{14}$, we can also prove that $d \tilde{Y}^{*} / d \tilde{\imath}_{T}<0$, that is, the terms of trade improve more in favor of the East, the wider the liberalization. Hence the first term in the RHS of (32) is also negative; further liberalizations unambiguously increase the welfare of workers already exposed to reform. They can buy formerly nontraded goods at a lower price and sell at a higher price to richer customers in the East.

Finally, can there be some workers who strictly gain from the reform, despite being themselves exposed? To answer that question, let us look at the most favorable case, i.e. that of full liberalization with $\tilde{\imath}_{T}=0$. Using (17) and (16) we find that workers in sector $i$ experience a positive wage jump if and only if:

$$
\left(L+L^{*} / a(i)\right) \int_{0}^{i_{T}} \frac{1}{L+L^{*} / a(j)} d j+\left(i_{C}-i_{T}\right) \frac{a\left(i_{C}\right)}{a(i)} \leq i_{C} .
$$

$$
\begin{aligned}
& { }^{14} \text { The derivative has the same sign as } \\
& \qquad \begin{aligned}
N= & -\left(1-i_{C}\right) \frac{L^{*} / a\left(\tilde{\imath}_{T}\right)}{L+L^{*} / a\left(\tilde{\imath}_{T}\right)}-L \int_{\tilde{\imath}_{T}}^{i_{T}} \frac{1}{L+L^{*} / a(i)} d i \\
& +\left(i_{C}-\tilde{\imath}_{T}\right) \frac{L}{L+L^{*} / a\left(\tilde{\imath}_{T}\right)} \\
= & -\left(1-i_{C}\right) \frac{L^{*} / a\left(\tilde{\imath}_{T}\right)}{L+L^{*} / a\left(\tilde{\imath}_{T}\right)}+\left(i_{C}-i_{T}\right) \frac{L}{L+L^{*} / a\left(\tilde{\imath}_{T}\right)} \\
& +\left(i_{T}-\tilde{\imath}_{T}\right) \frac{L}{L+L^{*} / a\left(\tilde{\imath}_{T}\right)}-L \int_{\tilde{\imath}_{T}}^{i_{T}} \frac{1}{L+L^{*} / a(i)} d i .
\end{aligned}
\end{aligned}
$$

Using (11), we can rewrite that as

$$
\begin{aligned}
N= & -\frac{\left(1-i_{C}\right) L^{*}}{L+L^{*} / a\left(\tilde{\imath}_{T}\right)}\left[\frac{1}{a\left(\tilde{\imath}_{T}\right)}-\frac{1}{a\left(i_{C}\right)}\right] \\
& -L\left[\int_{\tilde{\imath}_{T}}^{i_{T}}\left(\frac{1}{L+L^{*} / a(i)}-\frac{1}{L+L^{*} / a\left(\tilde{\imath}_{T}\right)}\right) d i\right] .
\end{aligned}
$$

The two quantities in brackets are clearly positive, hence $N<0$. 
Not surprisingly, that is more likely to hold, the greater the worker's comparative advantage $i$, and we have already seen that it cannot hold for $i=\tilde{\imath}_{T}=0$. Inspection of that formula also reveals that the exposed worker with the best comparative advantage, $i=i_{T}$, may either gain or lose. It gains if $a\left(i_{T}\right)$ is close to $a\left(i_{C}\right)$ but $a(i)$ is small relative to $a\left(i_{T}\right)$ for most values of $i<i_{T}$. In such a case, exposed workers gain if $i$ is greater than some critical value. Otherwise, all exposed workers lose.

To summarize this subsection findings: 